\title{
On Preconditions for Revolutionary Situations
}

In 1917-18 Finland experienced a revolutionary situation, with the worker movement being the main challenger to the established order. I will argue that the response of the movement to the revolutionary opportunity - which was initiated by the sudden collapse of Imperial Russia - followed rather directly from the process of mobilisation described in the preceding pages.

In Chapter 9 the coming of revolution itself will be analysed in the light of the process of Finnish state-making and nation-building. Both long-term and short-term developments are important. On the one hand, the relative weight of structural and institutional preconditions for the revolutionary process must be assessed. The characters of, first, the polity and the class structure and, second, the national movement and the working-class movement, all of which affected the preconditions for collective action in 1917-18, were shaped in the nineteenth and early twentieth centuries. On the other hand, the intricacies of World War I must also be taken into account. The two groups of factors interacted and induced the relatively well entrenched and non-revolutionary working-class movement to a revolution. Chapter 10 will examine the impact of the failed revolution on the existing state structures and on the processes of national and class integration. In short, Part II I will delineate the impact of certain structural preconditions on an event, the Finnish revolution, and the repercussions of this event back on those structures.

Of use here is Charles Tilly's model of the proximate causes of revolutionary situations, ${ }^{1}$ which is linked to his conception of organisation, mobilisation, and collective action, employed earlier. In deliberately focusing on revolutionary situations in general, not only on successful revolutions, his model suggests comparisons between all cases of serious revolutionary activity, irrespective of their outcome. This is particularly important in the analysis of small polities such as Finland. Although international factors have played a part in nearly all revolutions, ${ }^{2}$ only in the small polities has the final success or failure most evidently depended on fluctuations in international power constellations. In other words, it is specifically the rise of revolutions that is of interest here.

1 Tilly 1978, pp. 200-2.

2 See Dunn 1972, 1977; Skocpol 1979.

(C) KONINKLIJKE BRILL NV, LEIDEN, 2019 | DOI:10.1163/9789004386174_009

This is an open access chapter distributed under the terms of the CC BY-NC-ND $4_{R} 0$ license lapuro $_{\text {- }} 9789004386174$ 
In Tilly's view revolutions involve the seizure of control over a governmental apparatus by one class, group, or, more likely, a coalition of several groups. The revolutionary situation itself is defined by what Lenin and Trotsky called 'dual power' and Tilly terms 'multiple sovereignty': the fragmentation of governmental authority into two or more centres, each of which claims exclusive legitimacy. Multiple sovereignty has often emerged when the polity consisting of the collective action of those groups routinely making successful claims on the exercise of government in their interest - splits into conflicting factions. Such a fragmentation of the ruling establishment, moreover, may provide challengers from below with tactical opportunities to press their demands. ${ }^{3}$ By definition, there are three proximate causes of multiple sovereignty:

1. the appearance of contenders, or coalitions of contenders, advancing exclusive alternative claims to the control over the government which is currently exerted by the members of the polity;

2. commitment to those claims by a significant segment of the subject population (especially when those commitments are not simply acknowledged in principle, but activated in the face of prohibitions or contrary directives from the government);

3. incapacity or unwillingness of the agents of the government to suppress the alternative coalition and/or the commitment to its claims. ${ }^{4}$

The causes in Tilly's model are largely consecutive. They form the beginning of 'an idealized revolutionary sequence': first, gradual mobilisation of contenders; then, rapid increase in the number of people accepting those claims or rapid expansion of the alternative coalition; and finally, unsuccessful efforts by the government to suppress the alternative coalition. ${ }^{5}$

This 'idealised sequence', simple as it is, provides a helpful framework for analysing the Finnish case. It helps to relate existing forms of organisation and mobilisation to the opportunities created by the intricacies of World War I. Because the revolutionary situation was, in a sense, a conjunction of internal structural factors and short-term external factors (that is, the crisis in Russia), the framework also helps in assessing the relative importance of domestic and

3 Tilly 1978, pp. 190-3. The formulation here is based on Rod Aya's summary (1979, p. 44).

4 Tilly 1978 , p. 200.

5 Ibid., pp. 216-17. 
foreign developments. It will be suggested, for example, that the third proximate cause, the incapacity of the government to suppress the emerging polity, was particularly important in Finland.

In a more general perspective the specific features of the Finnish case may be clarified by Barrington Moore's discussion of the preconditions for 'major' revolutions. ${ }^{6}$ Moore concentrates on three preconditions in the dominant classes. The first is the decay of legitimacy: the whole intellectual and emotional structure that makes the prevailing order seem natural, legitimate, and inevitable begins to crumble in the face of embarrassing questions for which the prevailing orthodoxies gradually cease to provide satisfactory answers; in other words, an intellectual challenge arises for which conventional categories and explanations increasingly fail to make sense. Second, sharp conflicts of interest develop within the dominant classes. These appear as insoluble financial problems but are basically acute disagreements about how to resolve problems arising from new social relationships and, more specifically, about which social groups should pay the costs of these new arrangements. The third precondition is, however, decisive: the loss of unified control over the instruments of violence, that is, over the army and the police. They may refuse to obey, or a section of the dominant classes may break off and take with it a part of the armed forces, or a mixture of the two processes may occur.

Clearly this list is reminiscent of Tilly's. ${ }^{7}$ Particularly similar are the loss of unified control over the army and the government's incapacity to suppress commitment to alternative claims. But Moore's time perspective is longer, and he obviously delineates the central preconditions for so-called Great Revolutions - those of France, Russia, and China. In France, an intellectual structure fundamentally critical of the prevailing order developed well before 1789: the revolution was, in essence, a realisation of the intellectual vision of the Enlightenment, which swept through French culture in the late 17oos. Moreover, disagreements between the absolutist Bourbon monarchy and the aristocratic upper classes mounted during the decades preceding the revolution and finally led to a sharp conflict between the government and the Estates General. Third, in 1789 the monarchy lost control of the instruments of violence; it was unable to use the armed forces to impose its will.

The Russian sequence resembles the French one. 'Artists and intellectuals ... had long [before 1917] sung the coming of the revolution' is the way Marc Ferro expresses the first precondition. ${ }^{8}$ Also, the imperial state had started a

6 Moore 1972, pp. 170-5.

7 Cf. Tilly 1978, p. 201.

8 Ferro $1967-76,1: 143$. 
process of industrialisation that furthered the disintegration of old roles in various segments of society and displaced the gentry. ${ }^{9}$ Nonetheless, the ensuing conflicts among the dominant groups certainly were not as bitter as in France. World War I dealt the death blow to the autocracy, contributing especially to the dissolution of the army; after the devastating losses in war, the armed forces refused to obey.

The initial phases of the Chinese revolution are comparable to the other cases. The May Fourth Movement of 1919, a mass movement of intellectuals, was 'a kind of Chinese Enlightenment ... [that] foreshadowed and paved the way for 1949 just as Voltaire had for $1789 .{ }^{\prime 0}$ Besides, discontent among the privileged was rife before the onset of the revolutionary process, that is, before 1911. Many of the members of the revolutionary organisations were from the privileged classes. Soon the new republic crumbled, and rival warlords took over parts of the old armed forces and created their own private armies.

The three preconditions, pertinent as they are for the analysis of the two established European states and China, are less relevant for the revolutionary situations in Finland and other European latecomer states. In Finland, for one thing, the whole intellectual structure legitimising the prevailing order had only recently been constructed, and at the beginning of the twentieth century there was unanimity among all intellectual groups about the basic character of national integration. National identification was clear in the new working-class movement as well; it has even been seen as an outgrowth of the national tradition that originated with Snellman. ${ }^{11}$ Moreover, only a handful of intellectuals were active in the Social Democratic movement, and most of them had joined the party between 1904 and 19o6. Second, no major conflicts of interest existed within the dominant classes. Indeed, the rise of the working-class movement caused them to close ranks in the decade following the general strike of $1905 .{ }^{12}$

In these two respects the situation in the Eastern European polities was not too different. To be sure, certain countries, such as Hungary and Romania, had dissident intellectual groups, but it seems fair to say that conflicts within the dominant groups remained limited. With respect to national minorities, the preconditions do not really apply. True, national movements struggled for

\footnotetext{
$9 \quad$ Skocpol 1979, pp. 91-2.

$10 \quad$ Bianco 1971, pp. 27-8.

11 Palmgren 1948, pp. 184-204. Cf. Hamalainen 1978, pp. 30-3 and passim; and Hodgson 1967, pp. 7-8. One indication of the national identification in the worker movement is the active participation of certain socialist leaders in the nationalist organisation Suomalaisuuden liitto (League for the Finnish Culture) after 1906 (Hamalainen 1978, p. 135).

12 This tendency was particularly clear in the cultural sphere. See Murtorinne 1967, pp. 9o104, 222, 229, 231.
} 
self-assertion and liberation, and consequently came into conflict with dominant local groups that identified with the metropolitan country, but minority regions were not usually polities to the extent that Finland was. These movements strove more for the creation of new polities than for power in an already existing one, and severe conflicts remained rare within minority groups until World War I.

The third precondition, however, was absolutely crucial for revolutionary situations in all the latecomer states and dependent regions. The collapse of the two multinational empires in World War I led to the disintegration of the armed forces not only in the core areas of Russia and Austria-Hungary but also in their minority regions. The same was true, at least for brief periods, in Romania, Bulgaria, and Serbia. ${ }^{13}$ Opportunities to act collectively were thus thrust upon only modestly organised and mobilised nationalities.

The three preconditions highlight the differences between the established and the new European states delineated in Chapter 1. In the early cases, as exemplified by the French and Russian revolutions, long-term internal processes that prepared the ground for revolution may be discerned, involving not only conflicts within the dominant classes or between the elites and the central governments but also structural preconditions conducive to collective action among peasants and workers. The two processes - state/elite conflicts and popular uprisings - coincided in the revolutions. ${ }^{14}$ To cite Barrington Moore, a certain social process 'worked itself out' in these cases. ${ }^{15}$ This view is also in line with Theda Skocpol's analysis, ${ }^{16}$ although she systematically incorporates the international environment in the analysis of the three Great Revolutions. Actually, Skocpol studies long-term internal processes - that is, how domestic class structures and political institutions ultimately made it impossible for the imperial states to cope successfully with competition or intrusions from abroad. The decomposition of the armed forces under international pressure should be viewed against the background of these long-term internal processes.

In Eastern European latecomer polities, opportunities changed quite independently of the strength of domestic collective action. In these cases a shortterm external event, World War I, was crucial for the rise of revolutionary activity.

13 Steiner 1967, pp. 183, 189; Nagy 1967, p. 162; Moore 1978, pp. 291-309; Schärf 1967, pp. 2oo, 223-4.

14 See Goldstone 1982, pp. 194-200.

15 Moore 1966, p. xii.

16 Skocpol 1979, esp. pp. 112-17. 
The situation of these countries also seems to be systematically different from that of the small non-European polities that have experienced serious revolutionary activity in the twentieth century (that is, the colonial countries). These revolutionary situations have usually emerged after a hard, painful, and often slow process of organisation and mobilisation - accompanied, it is true, by repeated disruptions in colonial control. In typical cases a revolutionary situation was created only after decades or at least many years of 'patient institution-building. ${ }^{17}$ In this comparison too, then, the small European polities emerge as unique cases in which the rapid dissolution of the armed forces played a central role, while the other two preconditions and possibly even anteceding popular organisation were relatively unimportant.

The collapse of the most powerful continental states in 1917-18 created an exceptional opportunity for local forms of organisation and mobilisation to develop with a minimum of hindrance. It should be stressed that local attempts at revolution were genuinely internal: they took place within a polity, and the main contenders were indigenous groups. But there was no long-term 'preparation' for revolution comparable to that preceding the Great Revolutions or the anticolonial revolutions, and thus, in the Finnish case at least, this implies that there were few intellectual instruments for coping with the revolutionary attempt in the post-1918 culture. This qualification helps to relate the previous process of national and class integration not only to the revolution 1917-18 but also to the period following it.

In the next chapter the interplay of internal and external factors leading up to the revolutionary situation will be examined. The central task is to consider how the special characteristics of the internal revolutionary processes in Finland resulted from the country's external dependencies, given the long-term structural and institutional background presented above.

17 Migdal 1974, pp. 229-56, 265 (quotation). For an illuminating example of the slow process of revolutionary institution-building, see Popkin 1979, pp. 223-42. 